\title{
Computing two special cases of Gauss hypergeometric function
}

\section{MOHAMMAD MASJED-JAMEI and WOLFRAM KOEPF}

\section{ABSTRACT.}

In this paper, a computational technique is given to re-obtain the explicit forms of two cases of the Gauss hypergeometric function ${ }_{2} F_{1}(a, b, c ; x)$ for $b=a+1 / 2$ and $c=1 / 2,1 / 3$. Some special identities related to the two aforesaid cases are also introduced. Finally a special Maple package, called FormalPowerSeries (FPS), is used to automatically compute some results given in the paper.

Department of MATHEMATics

K. N. TOOSI UNIVERSITY OF TECHNOLOGY

P.O. BOX 16315-1618, TEHRAN, IRAN

E-mail address: mmjamei@kntu.ac.ir, mmjamei@yahoo.com

UNIVERSITY OF KASSEL

INSTITUTE OF MATHEMATICS

HeinRich-Plett-Str. 40, 34132 Kassel, Germany

E-mail address: koepf@mathematik.uni-kassel.de 